Anglia and the Broads; Birmingham and district; Tyneside and Lancashire, Yorkshire and Cheshire. These maps, with the 6-in. to the mile, are known as 'medium scale'. Full descriptions of other Ordnance Survey maps, with illustrations and indexes, are given in two pamphlets, one dealing with small-scale maps and the other large-scale maps, issued by the Director General, Ordnance Survey Office, Chessington, Surrey (1s. 6d. each).

\section{Research in Telecommunications}

The past decade has demonstrated the great importance of efficient and rapid communication as an essential part of modern civilization. Although in certain directions spectacular advances have been made in the development of telecommunications, which includes both radio and land-line signalling, there is more need now than hitherto for pursuing that fundamental research which underlies all the many applications of these techniques. In order to meet this need, the Department of Scientific and Industrial Research formed in 1946 an ad hoc Telecommunications Research Committee under the chairmanship of Sir Stanley Angwin, for the purpose of defining the basic problems in the whole field of telecommunications that would require investigation in the next few years. The Committee, which consisted of representatives of the radio industry, of those Government departments directly concerned with this subject, and of the British Broadcasting Corporation, drew up a report which has recently been published by the Department of Scientific and Industrial Research ("The Fundamental Research Problems of Telecommunications", London, H.M. Stationery Office, 1948. 1s. 6d. net).

This publication contains both the full reports and abstracts of the nine 'working parties' set up by the Committee to deal with the various phases of the subject. These working parties surveyed existing knowledge in their various fields to determine what deficiencies in that knowledge required attention; and they have indicated in considerable detail the specific items of research which appear to require investigation. It is believed that the formulation of these prob. lems will prove a very useful step forward in the development of telecommunications research in Great Britain, and it is to be emphasized that university research laboratories, as well as those of government and industry, will find in the document many items suitable for their attention. With the issue of this report, the Committee has completed the task assigned to it : but the Department of Scientific and Industrial Research has already constituted a Standing Conference on Telecommunications Research, the function of which is to survey periodically the progress being made in this subject, and to provide a means for consultation between the Department's Radio Research Board and industry on these and other such matters of common interest.

\section{Air Routes}

THE advent and growing use of air transport has done a great deal to alter geographical values. Speed has reduced the importance of distance and thus recast many political, economic and social relationships. In a small pamphlet recently published ("Air Transport and Geography." London: Royal Geographical Society, 1947. 1s.), Mr. W. G. V. Balchin refers to many of the aspects of geography that touch on the course and uses of air routes. After referring to the vexed problem of air maps and their projections, he inserts a world map on an oblique zenithal equidistant projection centred on London and its antipodal point; on this the chief civil routes are shown. These maps show that 94 per cent of the world's population, and nearly all the world's manufacturing industry, fall in one of these hemispheres, and the central hub is in western Europe with London or Paris the actual centre. The distribution of population, especially of large urban growths, determines the course of the chief air routes. There are some forty-four world areas each of more than a million inhabitants, of which the largest are in Europe and the Atlantic side of North America and fewest in Africa and in Asia, outside China and Japan. The greatest number are on a great circle track through London and Melbourne. Major flying routes do not cross the Pacific, and contrary to often expressed belief, do not pass through north polar regions. Mr. Balchin goes on to consider other factors influencing the course of air routes.

\section{Strawberries and Watercress as Commercial Crops}

BuLletin 95, "Strawberries" (London: H.M. Stationery Office. $2 s$. net), was originally published by the Ministry of Agriculture in 1937, but since that time so much new knowledge about the crop has become available that a new edition became necessary. This has now been accomplished with gratifying completeness, by co-operation between the scientific staffs of Long Ashton and East Malling Research Stations. All aspects of culture are discussed; but such items of practice as relate to the propagation and maintenance of healthy stocks receive special mention. One section deals with newer methods of out-of-season production, and an appendix describes the recognition of varieties. The section on diseases and pests is adequate; but prompts the gentle criticism that it is scarcely complete enough to deal with some troubles which are common in the northern part of Britain. Twenty-seven good half-tone figures add greatly to the value of the bulletin.

Watercress cultivation is a fascinating speciality. Bulletin 136 (London : H.M. Stationery Office. Is. net) is written by Mr. Charles H. Sansom, and gives details of all aspects of this crop. Continuous growth is given by water at about $50^{\circ} \mathrm{F}$., and it is often best to obtain this by boring through chalk to a depth of $300 \mathrm{ft}$. This special crop brings special pests, for the freshwater shrimp (Gammarus sp.) and caddis fly larvæ cause some damage, as well as the mustard beetle. Eight plates and diagrams show details of establishment and management of the beds.

\section{Mushroom Diseases}

Bulletin No. 10 of the Mushroom Growers' Association (Yaxley, Peterborough. 2s. 6d, net) contains a brief note by F. C. Atkins and C. J. La Touche on Pseudobalsamia microspora, an ascomycete which may compete with the mushroom on commercial beds. It is almost certainly introduced with the surface soil and so can possibly be eliminated with care. Boards and the house-structure should be sterilized and flies kept down, as they spread the trouble. The same bulletin contains reprints of Dr. W. M. Ware's paper on "Clitopilus cretatus as an Invader of Mushroom Beds" (Gard. Chron., May 18, 1935), and Dr. W. F. Bewley's work on mushroom casing soil (Cheshunt Exp. Sta. Ann. Rep., 1946). A separate leaflet lists useful volumes on mushroom culture in the Association's library. 